\title{
A Survey of Korean Physicians' Prescription Patterns for Allergic Rhinitis
}

\author{
Min Young Seo $\cdot$ Dong-Kyu Kim² $\cdot$ Hye Mi Jee ${ }^{3}$ Young Min Ahn $\cdot$ Yong Min Kim ${ }^{5}$ Sang Duk Hong ${ }^{1}$ \\ Work Group for Allergic Rhinitis of the Korean Academy of Asthma, Allergy and Clinical Immunology (KAAACl) \\ ${ }^{\prime}$ Department of Otorhinolaryngology-Head and Neck Surgery, Samsung Medical Center, Sungkyunkwan University School of Medicine, Seoul; \\ ${ }^{2}$ Department of Otorhinolaryngology-Head and Neck Surgery, Chuncheon Sacred Heart Hospital and Nano-Bio Regenerative Medical Institute, \\ Hallym University College of Medicine, Chuncheon, ${ }^{3}$ Department of Pediatrics, CHA Bundang Medical Center, CHA University, Seongnam; \\ ${ }^{4}$ Department of Pediatrics, Eulji General Hospital, Eulji University School of Medicine, Seoul; ${ }^{5}$ Department Otorhinolaryngology-Head and Neck \\ Surgery, Chungnam National University School of Medicine, Daejeon, Korea
}

Objectives. The aim of this study was to compare the prescription patterns according to characteristics of physicians using a survey distributed amongst physicians in Korea.

Methods. We surveyed the prescription patterns for allergic rhinitis (AR) of the members of the Korean Academy of Asthma, Allergy and Clinical Immunology (KAAACI) and the Korean Association of Otorhinolaryngologists (KAO). Questionnaire contained 4 categories with 28 queries. 448 physicians including 98 internal medicine (IM), 113 pediatrics (PED), and 237 otorhinolaryngology (ENT) were responded.

Results. Although the Allergic Rhinitis and its Impact on Asthma (ARIA) guidelines are most frequently used in all specialties, seasonal or perennial AR is the most frequent classification system. For the definitive diagnosis of AR, ENT physicians reported using multiple allergen simultaneous test (MAST)/radio allergy sorbent test (RAST) more than others (IM, 10.9\%; PED, 20.6\%; ENT, 44.2\%; $P<0.001$ ). In treatment, most physicians reported that antihistamine medication is the initial treatment for AR. PED physicians prescribed fewer intranasal steroid to combinations with an antihistamine than other specialists (IM, 65.3\%; PED, 42.5\%; ENT, 63.3\%), but preferred leukotriene antagonists (IM, 4.1\%; PED, 23.0\%; ENT, 3.9\%; $P=0.041)$. Overall, 53\% (235/448) of the physicians performed allergen immunotherapy (AIT), and IM administers the most AIT (IM, 71.6\%; PED, 42.0\%; ENT, 39.5\%; $P=0.019$ ). Furthermore, university and general hospital physicians prescribed more AIT than doctors at other hospital types (university hospital, 76.4\%; general hospital, 64.3\%; local hospital, 21.4\%; private clinic, $20.2 \%$; $P<0.001$ ).

Conclusion. The prescription patterns for AR were different according to the physicians' characteristics and general rate of prescribing AIT is just about $53 \%$ in Korea. Thus, the development of complementary Korean-specific guidelines is needed and proper clinical instruction of AIT would be necessary.

Keywords. Allergic Rhinitis; Drug Prescriptions; Surveys and Questionnaires

- Received February 2, 2017

Revised March 22, 2017

Accepted April 3, 2017

- Corresponding author: Sang Duk Hong

Department of Otorhinolaryngology-Head and Neck Surgery, Samsung

Medical Center, Sungkyunkwan University School of Medicine, 81 Irwonro, Gangnam-gu, Seoul 06351, Korea

Tel: +82-2-3410-3579, Fax: +82-2-3410-3879, E-mail: kkam97@gmail.com

- Co-Corresponding author: Hye Mi Jee

Department of Pediatrics, CHA Bundang Medical Center, CHA University, 59 Yatap-ro, Bundang-gu, Seongnam 13496, Korea

Tel: +82-31-780-5229, Fax: +82-31-780-5239, E-mail: hyemijee@gmail.com

*The first two authors contributed equally to this study.

\section{INTRODUCTION}

Allergic rhinitis (AR) is one of the most common diseases in rhinologic and allergic clinics; the prevalence was $18.5 \%-28 \%$ and the mean annual cost for AR patients was about $\$ 18,000$ in Korea [1-3]. Several clinical guidelines proposed by various organizations have been used on AR, and the prescription patterns vary by characteristics of physicians [4-7]. Furthermore, allergen immunotherapy (AIT) is the only medical intervention that

Copyright @ 2017 by Korean Society of Otorhinolaryngology-Head and Neck Surgery

This is an open-access article distributed under the terms of the Creative Commons Attribution Non-Commercial License (http://creativecommons.org/licenses/by-nc/4.0)

which permits unrestricted non-commercial use, distribution, and reproduction in any medium, provided the original work is properly cited. 
modifies the natural course of AR, but it is not popular in Korea compared to Western countries [8]. Thus, an assessment of common diagnostic and therapeutic prescription patterns for AR is essential for recommending the proper management of AR to primary physicians; however, no data are available for Korean populations. Therefore, the aim of this study was to compare the prescription patterns of AR according to specialties and affiliated practice types of physicians in Korea.

\section{MATERIALS AND METHODS}

A survey of members of the Korean Academy of Asthma, Allergy and Clinical Immunology (KAAACI) and the Korean Association of Otorhinolaryngologists (KAO) was performed between May and September 2016. The authors used both online and offline survey methods. The survey contained 28 questions and was divided into four categories: demographics, diagnosis, treatment, and AIT. The responses were anonymous, and no personal information was collected (Supplementary Table 1). Prescription patterns were compared according to the physicians' specialties (internal medicine [IM], pediatrics [PED], and otorhinolaryngology [ENT]) and practice types (university hospital, general hospital, local hospital, and private clinic). The statistical analysis was carried out using a chi-square test. To avoid demographical discordance, the authors adjusted the practice type and physician specialty with a multinomial regression. All statistical analyses were approved by the Biostatistics and Clinical Epidemiology Center of Samsung Medical Center and performed with the R software ver. 3.3.0 (R Foundation for Statistical Computing, Vienna, Austria; http://www.R-project.org). A $P$-value less than 0.05 was considered statistically significant.

\section{RESULTS}

\section{Demographic data}

A total of 448 physicians responded to the questionnaire, and the numbers of IM, PED, and ENT physicians were 98, 113, and

\section{H I G G H L I G G H T S}

- ENT physicians reported multiple allergen simultaneous test/ radio allergy sorbent test more than others for diagnosis of allergic rhinitis.

- Pediatrics (PED) physicians preferred leukotriene antagonists than intranasal steroid to combination with an antihistamine.

- ENT and PED physicians prescribed less allergen immunotherapy (AIT) than internal medicine physicians.

- University and general hospital physicians prescribed more AIT than physicians at local hospital and private clinic.
237, respectively. Of the 448 responders, 149, 36, 28, and 235 physicians worked at university hospitals, general hospitals, local hospitals, and private clinics, respectively (Table 1).

\section{Diagnosis}

Most physicians reported that the patients' symptoms were the most important parameter for the diagnosis of AR and showed no significant difference according to physician specialty (IM, $86.5 \%$; PED, $88.8 \%$; ENT, 78.4\%; $P=0.177$ ). However, for a definitive diagnosis of AR, ENT physicians used multiple allergen simultaneous test (MAST)/radio allergy sorbent test (RAST) more than others (IM, 10.9\%; PED, 20.6\%; ENT, 44.2\%), and this result was statistically significant $(P<0.001)$ (Fig. 1). Furthermore, the physicians who worked in university hospitals used skin prick testing most often (university hospital, 75.7\%; general hospital, 37.5\% ; local hospital, 18.5\%; private clinic, $37.7 \%$ ), but this difference had no statistical significance $(P=0.182)$.

Physicians used various parameters to diagnose AR, with the most popular being the ARIA guidelines (IM, 54.7\%; PED, $62.0 \%$; ENT, 53.3\%). Furthermore many ENT physicians also used the Korean Rhinologic Society (KRS) guidelines (25.8\%), while PED and IM physicians preferred the KAAACI guidelines (26.9\% and $38.4 \%$, respectively). However; about $12.1 \%$ of physicians used no guidelines for AR; and this tendency increased with a lower hospital grade (university hospital, 4.3\%; general hospital, 9.1\%; local hospital, 14.3\%; private clinic, $17.2 \%)$. In addition; the authors also found that ENT physicians used guidelines less frequently than other specialists (IM, 7.0\%;

Table 1. Demographic data of the responding physicians

\begin{tabular}{lrrrr}
\hline Variable & IM & PED & ENT & Total \\
\hline University hospital & 72 & 46 & 31 & 149 \\
General hospital & 11 & 12 & 13 & 36 \\
Local hospital & 4 & 18 & 6 & 28 \\
Private clinic & 11 & 37 & 187 & 235 \\
Total & 98 & 113 & 237 & 448 \\
\hline
\end{tabular}

IM, internal medicine; PED, pediatrics; ENT, otorhinolaryngology.

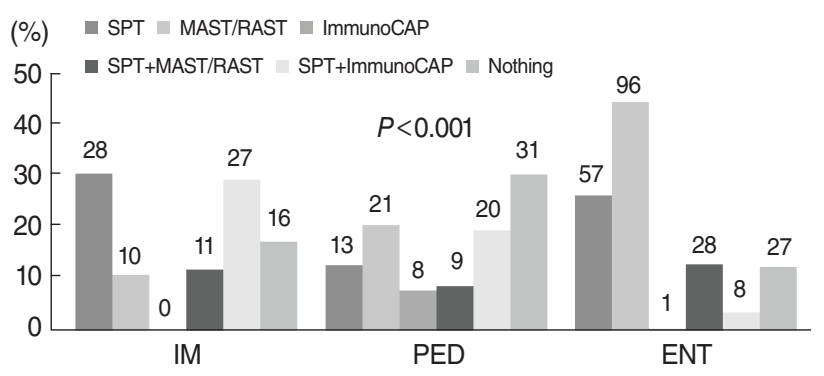

Fig. 1. Prescription patterns for the definitive diagnosis of allergic rhinitis according to physician specialty. The number in the bar graph indicates the number of patients in each category. IM, internal medicine; PED, pediatrics; ENT, otorhinolaryngology; SPT, skin prick test; MAST, multiple allergen simultaneous test; RAST, radio allergy sorbent test. Statistical analysis is chi-square test with multinomial regression. 
Table 2. Distribution of guidelines for the diagnosis and treatment of allergic rhinitis according to physician characteristics

\begin{tabular}{|c|c|c|c|c|c|c|c|c|c|}
\hline \multirow[b]{2}{*}{ Variable } & \multicolumn{4}{|c|}{ Physicians' specialty } & \multicolumn{5}{|c|}{ Practice type } \\
\hline & $\underset{(n=88)}{I M}$ & $\begin{array}{c}\text { PED } \\
(n=108)\end{array}$ & $\begin{array}{c}\text { ENT } \\
(n=229)\end{array}$ & $P$-value & $\begin{array}{l}\text { University } \\
\text { hospital } \\
(n=140)\end{array}$ & $\begin{array}{c}\text { General } \\
\text { hospital } \\
(n=33)\end{array}$ & $\begin{array}{c}\text { Local } \\
\text { hospital } \\
(n=28)\end{array}$ & $\begin{array}{c}\text { Private } \\
\text { clinic } \\
(n=227)\end{array}$ & $P$-value \\
\hline ARIA & 54.7 & 62.0 & 53.3 & 0.036 & 64.3 & 57.6 & 28.6 & 52.0 & 0.001 \\
\hline AAO-HNSF & 0 & 0.9 & 1.8 & & 0.7 & 0 & 3.6 & 1.3 & \\
\hline KAAACI & 38.4 & 26.9 & 3.5 & & 27.1 & 15.2 & 42.9 & 7.9 & \\
\hline KRS & 0 & 1.9 & 25.8 & & 2.1 & 18.2 & 10.7 & 21.6 & \\
\hline Others & 0 & 0 & 0 & & 1.4 & 0 & 0 & 0 & \\
\hline Nothing & 7.0 & 8.3 & 15.7 & & 4.3 & 9.1 & 14.3 & 17.2 & \\
\hline
\end{tabular}

Values are presented as percentage. Statistical analysis is chi-square test with multinomial regression.

IM, internal medicine; PED, pediatrics; ENT, otorhinolaryngology; ARIA, Allergic Rhinitis and its Impact on Asthma; AAO-HNSF, American Academy of Otolaryngology-Head and Neck Surgery Foundation; KAAACI, Korean Academy of Asthma, Allergy and Clinical Immunology; KRS, Korean Rhinologic Society.

Table 3. Distribution of combination treatment patterns for allergic rhinitis according to the physicians' specialties

\begin{tabular}{|c|c|c|c|c|}
\hline Variable & $\mathrm{IM}(\mathrm{n}=98)$ & $\operatorname{PED}(n=113)$ & ENT $(n=237)$ & $P$-value \\
\hline Intranasal steroid+antihistamine & 65.3 & 42.5 & 63.3 & 0.041 \\
\hline Intranasal steroid+intranasal antihistamine & 0 & 2.7 & 2.6 & \\
\hline Intranasal steroid+leukotriene antagonist & 0.5 & 6.2 & 0.4 & \\
\hline Antihistamine+leukotriene antagonist & 4.1 & 23.0 & 3.9 & \\
\hline Antihistamine+decongestant & 6.1 & 0.9 & 7.3 & \\
\hline Intranasal steroid+antihistamine+leukotriene antagonist & 17.4 & 21.2 & 7.7 & \\
\hline Intranasal steroid+antihistamine+decongestant & 2.0 & 3.5 & 14.5 & \\
\hline Others & 0 & 0 & 0.4 & \\
\hline
\end{tabular}

Statistical analysis: chi-square test with multinomial regression.

IM, internal medicine; PED, pediatrics; ENT, otorhinolaryngology.

PED, 8.3\%; ENT, 15.7\%), and these results were statistically significant $(P=0.036)$ (Table 2).

\section{Treatment}

Most physicians reported that antihistamine medication is the initial treatment for AR and showed no difference according to physician specialty (IM, 61.5\%; PED, 64.2\%; ENT, 65.4\%). Intranasal antihistamines were the most common initial treatment recommended by ENT physicians (23.5\%), while intranasal steroids were primarily prescribed by PED and IM physicians (19.8\% and $27.1 \%$, respectively); the difference was not statistically significant $(P=0.979)$.

The authors also evaluated the patterns of combination therapy and identified a difference according to physician specialty. PED specialists prescribed fewer intranasal steroid and antihistamine combinations than other specialists (IM, 65.3\%; PED, $42.5 \%$; ENT, $63.3 \%$ ). However they also were most likely to prescribe a leukotriene antagonist instead of an intranasal steroid (IM, 4.1\%; PED, 23.0\%; ENT, 3.9\%). These results were statistically significant $(P=0.041)$ (Table 3).

Local hospital physicians were the least likely to recommend surgery for rhinitis than clinicians at other practice types (university hospital: $69.2 \%$, general hospital: $61.1 \%$, local hospital: $39.9 \%$, private clinic: $68.7 \%, P=0.011$ ). When the different types of physician specialties were assessed, PED practitioners also were not very likely to recommend surgery (IM, 65.6\%; PED, 38.4\%; ENT, 79.9\%; $P<0.001)$.

\section{Allergen immunotherapy}

Only respondents who performed AIT were asked to complete the remainder of the questionnaire. Among the 448 surveyed physicians, 235 physicians offered AIT, and IM physicians performed more AIT than PED or ENT physicians (IM, 71.6\%; PED, $42.0 \%$; ENT, 39.5\%), the difference was statistically significant $(P=0.019)$. The authors also noted a difference according to practice types, university and general hospital physicians performed more AIT than their counterparts at local hospitals and clinics (university hospital, $76.3 \%$; general hospital, $64.3 \%$; local hospital, $21.4 \%$; private clinic, $20.2 \%$ ), which was statistically significant $(P<0.001)$ (Table 4$)$. The three most frequently mentioned reasons for not performing AIT were "distrust of its therapeutic effect," "requirement of a long-term treatment duration," and "lack of facilities or trained health professionals."

When asked about the method used to administer AIT, the respondents reported different patterns according their specialties and practice types. University and general hospital physicians preferred subcutaneous immunotherapy (SCIT) to sublingual immunotherapy (SLIT), but local hospital and private clinic physicians were more likely to choose SLIT. Furthermore, IM and PED physicians recommended SCIT, but ENT physicians had a 
Table 4. The prescription rate of allergen immunotherapy according to physician characteristics

\begin{tabular}{|c|c|c|c|c|c|c|c|c|c|}
\hline \multirow[b]{2}{*}{ Variable } & \multicolumn{4}{|c|}{ Physicians' specialty } & \multicolumn{5}{|c|}{ Practice type } \\
\hline & $\underset{\substack{\mathrm{IM} \\
(\mathrm{n}=95)}}{ }$ & $\begin{array}{c}\text { PED } \\
(n=112)\end{array}$ & $\begin{array}{c}\text { ENT } \\
(n=233)\end{array}$ & $P$-value & $\begin{array}{c}\text { University } \\
\text { hospital } \\
(n=148)\end{array}$ & $\begin{array}{c}\text { General } \\
\text { hospital } \\
(n=35)\end{array}$ & $\begin{array}{c}\text { Local } \\
\text { hospital } \\
(n=28)\end{array}$ & $\begin{array}{c}\text { Private } \\
\text { clinic } \\
(n=232)\end{array}$ & $P$-value \\
\hline None & 28.4 & 58.0 & 60.5 & 0.019 & 23.7 & 45.7 & 78.6 & 69.8 & $<0.001$ \\
\hline$\leq 10 \%$ & 31.6 & 25.0 & 32.6 & & 38.5 & 34.3 & 14.3 & 26.7 & \\
\hline $11 \%-20 \%$ & 23.2 & 8.9 & 4.3 & & 20.3 & 11.4 & 3.6 & 3.0 & \\
\hline $21 \%-30 \%$ & 9.5 & 6.3 & 1.3 & & 10.8 & 5.7 & 3.6 & 0 & \\
\hline $31 \%-40 \%$ & 4.2 & 1.8 & 0.4 & & 4.7 & 0 & 0 & 0 & \\
\hline$>40 \%$ & 3.2 & 0 & 0.9 & & 2.0 & 2.9 & 0 & 0.4 & \\
\hline
\end{tabular}

Values are presented as percentage. Statistical analysis is chi-square test with multinomial regression. IM, internal medicine; PED, pediatrics; ENT, otorhinolaryngology.

Table 5. Prescription patterns by allergen immunotherapy method

\begin{tabular}{|c|c|c|c|c|c|c|c|c|c|}
\hline \multirow[b]{2}{*}{ Variable } & \multicolumn{4}{|c|}{ Physicians' specialty } & \multicolumn{5}{|c|}{ Practice type } \\
\hline & $\underset{(n=64)}{I M}$ & $\begin{array}{c}\text { PED } \\
(n=43)\end{array}$ & $\begin{array}{c}\text { ENT } \\
(n=94)\end{array}$ & $P$-value & $\begin{array}{c}\text { University } \\
\text { hospital } \\
(n=107)\end{array}$ & $\begin{array}{c}\text { General } \\
\text { hospital } \\
(n=18)\end{array}$ & $\begin{array}{c}\text { Local } \\
\text { hospital } \\
(n=8)\end{array}$ & $\begin{array}{c}\text { Private } \\
\text { clinic } \\
(n=69)\end{array}$ & $P$-value \\
\hline SCIT & 53.1 & 37.2 & 31.9 & 0.142 & 36.5 & 61.1 & 37.5 & 37.7 & 0.23 \\
\hline SLIT & 7.8 & 14.0 & 48.9 & & 21.5 & 11.1 & 62.5 & 39.1 & \\
\hline Both & 35.9 & 48.8 & 13.8 & & 40.2 & 27.8 & 0 & 15.9 & \\
\hline Others & 3.1 & 0 & 5.3 & & 1.9 & 0 & 0 & 7.3 & \\
\hline
\end{tabular}

Values are presented as percentage. Statistical analysis is chi-square test with multinomial regression.

SCIT, subcutaneous immunotherapy; SLIT, sublingual immunotherapy.

preference for SLIT. This difference was not statistically significant (Table 5). Most physicians recommended a 3-year duration of AIT, and there was no difference in the required amount of time for AIT according to physician specialty or practice type.

The respondents who performed AIT were asked which allergens they used for AIT. The most preferred antigen was the house dust mite (HDM) followed by pollen. In addition, IM physicians had a greater preference for pollen than HDM and others, and this distinction was statistically significant (IM, 38.9\% vs. $29.1 \%$; PED, $44.1 \%$ vs. $26.1 \%$; ENT, $67.9 \%$ vs. $20.4 \%$; $P=0.001)$. Our study also found that IM physicians preferred to prescribe poly allergens for AIT; whereas physicians in other specialties did not favor poly allergens (IM, 64.3\%; PED, 48.9\%; ENT, $41.3 \% ; P=0.003)$.

Side effects of AIT were more common in SCIT than they were for SLIT, but ENT physicians reported fewer side effects for SCIT and a higher side effect rate for SLIT than physicians in other specialties (IM, $66 \%$ vs. $5.4 \%$; PED, $64 \%$ vs. $12 \%$; ENT, $25.5 \%$ vs. $20.5 \%$; $P=0.005)$.

\section{DISCUSSION}

In the present study, we identified a different prescribing pattern between physicians according to their specialty or practice type. All physicians primarily used the ARIA guidelines for their diag- noses, but ENT physicians used different secondary guidelines than the others. Furthermore, the percentage of physicians who used no guidelines gradually increased with a lower hospital grade and amongst ENT physicians. Because the ENT group contained more local clinic physicians than any other specialty, we performed an adjustment for this demographic discrepancy to allow us to recommend a proper guideline for ENT and local clinic physicians. Furthermore, a previous study mentioned that a vast majority of allergic patients in Korea are treated by ENTs and $73 \%$ of ENT specialists thought the ARIA guidelines are not suitable for daily care practice, although $60 \%$ follow ARIA guidelines $[3,9,10]$. Therefore, the use of proper guidelines by ENT physicians is very important for public health, and thus the development of a complementary Korean-specific guideline is necessary.

In the present study, ENT physicians used MAST or RAST more than other specialties. Because the accuracy rates of MAST/RAST for detecting sensitization to allergens are worse (MAST: $81.8 \%$ sensitivity, $89.5 \%$ specificity, and $86.4 \%$ efficiency; RAST: $85.8 \%, 87.5 \%$, and $86.2 \%$, respectively) than those of SPT or ImmunoCAP (93.2\% sensitivity, 97.8\% specificity, and 93.2\% efficiency) [11-13], either SPT or ImmunoCAP is recommended for a definitive diagnosis. If SPT cannot be used due to medication or skin problems, ImmunoCap must be considered first. However, because only 6 allergens are checked by ImmunoCap under the Korean insurance system, MAST/ RAST is often used in some situations as a second-best line of 
testing. For a more accurate diagnosis of AR, further education about the limitations of MAST/RAST will be required.

In our study, PED physicians demonstrated a different pattern of combination therapy. Although a majority of them prescribed antihistamines with intranasal steroids, a larger percentage of them preferred antihistamines along with a leukotriene antagonist. However, this difference in clinical behavior is expected because the 2010 ARIA revision guidelines recommended antihistamines in conjunction with leukotriene antagonists in preschool children with persistent AR [14]. However, the combination effect remains controversial in adults [7]. The 2010 ARIA revision guidelines suggested that antihistamines with a leukotriene antagonist were effective only in adults with seasonal AR [14]. Furthermore, Wheatley and Togias [15] suggested that although some randomized trials have shown a benefit of adding montelukast to an antihistamine, this combination should be reserved for patients whose symptoms are inadequately controlled with an antihistamine alone and who do not wish to use a glucocorticoid nasal spray.

In this survey, half of the physicians did not prescribe AIT for AR. The main reason they were reluctant to do so was because $29.1 \%$ of the respondents distrusted the efficacy of AIT for AR management. About $30.2 \%$ of the respondents did not prescribe AIT due to a lack of facilities or health professional, and 27.6\% stated that they did not recommend AIT due to the long-term treatment duration required. In our study, we did not assess the necessity of AIT for AR treatment. Hur et al. [8] reported that 98.6\% of physicians agreed on the necessity of AIT for treating allergic disease in Korea. In addition, a Chinese survey conducted among ENT specialists reported that $96.0 \%$ of the respondents considered AR to be the most suitable indication for AIT [16]. Despite these results, many physicians still do not prescribe AIT, even in patients where it is clinically indicated. However, the efficacy and safety of AIT and its prevention of asthma progression have been established by many studies [17-22]. In addition, one randomized clinical trials have shown that in AIT group a $58 \%$ reduction in symptom scores and a $20 \%$ reduction in the use of rescue medication after 1 year of treatment [23]. Furthermore, the effect of AIT maintained up to 7 years after treatment, when it was performed for 3 years [24]. Thus, PED and ENT specialists should be more concerned about AIT, and proper clinical instruction for local hospital and private clinic physicians will be necessary to encourage AIT.

In the present study, the most preferred antigen was HDM, followed by pollen. In Korea, HDM is also the most common allergen, followed by pollen, so the clinicians' prescribing patterns reflected their natural environment [25]. Although IM physicians preferred to use poly allergens for AIT and other specialists did not, more supporting data will be required to recommend its proper management since the use of single or multi-allergen AIT is still debatable in poly sensitized patients $[10,26]$. Amar et al. [27] reported that AIT with multiple allergens was not superior to monotherapy alone, but Nelson [28] concluded that the simultaneous administration of more than one allergen extract is clinically effective.

Our study is the first study to compare the diagnostic and therapeutic behavior of AR according to physicians' specialties and practice types in Korea. Although a similar survey for prescription patterns of AIT was previously conducted, it was confined to AIT alone [8]. However, the present study had some limitations. First, this survey was performed using both on-line and off-line methods; thus, we could not calculate the response rate. Second, the different practice types were not equally distributed across the physicians' specialties. For example, ENT physicians largely worked at private clinics, and IM physicians were predominantly employed at university hospitals. However, the authors consulted a biostatistics specialist to adjust this unequal distribution using a multinomial regression analysis and then considered this limitation to be resolved.

In conclusion, the prescription patterns for the diagnosis and treatment of AR were different according to distinct physician characteristics observed in Korea. Thus, the development of complementary Korean-specific guidelines is suggested along with proper clinical instruction about AIT.

\section{CONFLICT OF INTEREST}

No potential conflict of interest relevant to this article was reported.

\section{ACKNOWLEDGMENTS}

This study was supported by the Work Group for Allergic Rhinitis of the Korean Academy of Asthma, Allergy and Clinical Immunology (KAAACI).

\section{SUPPLEMENTARY MATERIAL}

Supplementary Table 1. Questionnaire regarding the prescription patterns for allergic rhinitis. This table can be found via https://doi. org/10.21053/ceo.2017.00143.

\section{REFERENCES}

1. Ahn JC, Kim JW, Lee CH, Rhee CS. Prevalence and risk factors of chronic rhinosinusitus, allergic rhinitis, and nasal septal deviation: results of the Korean National Health and Nutrition Survey 20082012. JAMA Otolaryngol Head Neck Surg. 2016 Feb;142(2):162-7.

2. Cho YS, Choi SH, Park KH, Park HJ, Kim JW, Moon IJ, et al. Prevalence of otolaryngologic diseases in South Korea: data from the Korea national health and nutrition examination survey 2008. Clin 
Exp Otorhinolaryngol. 2010 Dec;3(4):183-93.

3. Yoo KH, Ahn HR, Park JK, Kim JW, Nam GH, Hong SK, et al. Burden of respiratory disease in Korea: an observational study on allergic rhinitis, asthma, COPD, and rhinosinusitis. Allergy Asthma Immunol Res. 2016 Nov;8(6):527-34.

4. Bousquet J, Khaltaev N, Cruz AA, Denburg J, Fokkens WJ, Togias A, et al. Allergic Rhinitis and its Impact on Asthma (ARIA) 2008 update (in collaboration with the World Health Organization, GA(2) LEN and AllerGen). Allergy. 2008 Apr;63 Suppl 86:8-160.

5. Seidman MD, Gurgel RK, Lin SY, Schwartz SR, Baroody FM, Bonner JR, et al. Clinical practice guideline: allergic rhinitis. Otolaryngol Head Neck Surg. 2015 Feb;152(1 Suppl):S1-43.

6. Korean Rhinologic Society. Guidelines for allergic rhinitis. Seoul: Korean Rhinologic Society; 2012.

7. Korean Academy of Asthma, Allergy and Clinical Immunology. Guidelines for clinicians: allergic rhinitis. Seoul: Korean Academy of Asthma, Allergy and Clinical Immunology; 2015.

8. Hur GY, Kim TB, Han MY, Nahm DH, Park JW; Allergen and Immunotherapy Work Group of the Korean Academy of Asthma, Allergy and Clinical Immunology (KAAACI). A survey of the prescription patterns of allergen immunotherapy in Korea. Allergy Asthma Immunol Res. 2013 Sep;5(5):277-82.

9. Dhong HJ. Classification of allergic rhinitis: what is most suitable in Korea? Allergy Asthma Immunol Res. 2013 Mar;5(2):65-7.

10. Rhee CS. Current specific immunotherapy for allergic rhinitis: perspectives from otorhinolaryngologists. Allergy Asthma Immunol Res. 2014 Jul;6(4):273-5.

11. Jung YG, Cho HJ, Park GY, Min JY, Kim HY, Dhong HJ, et al. Comparison of the skin-prick test and Phadia ImmunoCAP as tools to diagnose house-dust mite allergy. Am J Rhinol Allergy. 2010 MayJun;24(3):226-9.

12. Bousquet J, Chanez P, Chanal I, Michel FB. Comparison between RAST and Pharmacia CAP system: a new automated specific IgE assay. J Allergy Clin Immunol. 1990 Jun;85(6):1039-43.

13. Scolozzi R, Vicentini L, Boccafogli A, Camerani A, Pradella R, Cavallini A, et al. Comparative evaluation of RAST and MAST-CLA for six allergens for the diagnosis of inhalant allergic disease in 232 patients. Clin Exp Allergy. 1992 Feb;22(2):227-31.

14. Brozek JL, Bousquet J, Baena-Cagnani CE, Bonini S, Canonica GW, Casale TB, et al. Allergic Rhinitis and its Impact on Asthma (ARIA) guidelines: 2010 revision. J Allergy Clin Immunol. 2010 Sep;126(3): 466-76.

15. Wheatley LM, Togias A. Clinical practice: allergic rhinitis. N Engl J Med. 2015 Jan;372(5):456-63.

16. Zhou H, Tao QL, Wei JM, Xu G, Cheng L. Trends in specific immu- notherapy for allergic rhinitis: a survey of chinese ENT specialists. Allergy Asthma Immunol Res. 2014 Jul;6(4):296-303.

17. Lin Z, Liu Q, Li T, Chen D, Chen D, Xu R. The effects of house dust mite sublingual immunotherapy in patients with allergic rhinitis according to duration. Int Forum Allergy Rhinol. 2016 Jan;6(1):82-7.

18. Cingi C, Bayar Muluk N, Ulusoy S, Acar M, Sirin S, Cobanoglu B, et al. Efficacy of sublingual immunotherapy for house dust mite allergic rhinitis. Eur Arch Otorhinolaryngol. 2015 Nov;272(11):3341-6.

19. Cardona V, Luengo O, Labrador-Horrillo M. Immunotherapy in allergic rhinitis and lower airway outcomes. Allergy. 2017 Jan;72(1): 35-42.

20. Kim SH, Mun SJ, Han DH, Kim JW, Kim DY, Rhee CS. Three-year follow-up results of sublingual immunotherapy in patients with allergic rhinitis sensitized to house dust mites. Allergy Asthma Immunol Res. 2015 Mar;7(2):118-23.

21. Marogna M, Spadolini I, Massolo A, Canonica GW, Passalacqua G. Long-lasting effects of sublingual immunotherapy according to its duration: a 15-year prospective study. J Allergy Clin Immunol. 2010 Nov;126(5):969-75.

22. Dretzke J, Meadows A, Novielli N, Huissoon A, Fry-Smith A, Meads C. Subcutaneous and sublingual immunotherapy for seasonal allergic rhinitis: a systematic review and indirect comparison. J Allergy Clin Immunol. 2013 May;131(5):1361-6.

23. Varney VA, Tabbah K, Mavroleon G, Frew AJ. Usefulness of specific immunotherapy in patients with severe perennial allergic rhinitis induced by house dust mite: a double-blind, randomized, placebocontrolled trial. Clin Exp Allergy. 2003 Aug;33(8):1076-82.

24. Jacobsen L, Niggemann B, Dreborg S, Ferdousi HA, Halken S, Host A, et al. Specific immunotherapy has long-term preventive effect of seasonal and perennial asthma: 10-year follow-up on the PAT study. Allergy. 2007 Aug;62(8):943-8.

25. Kim TB, Kim KM, Kim SH, Kang HR, Chang YS, Kim CW, et al. Sensitization rates for inhalant allergens in Korea; a multi-center study. J Asthma Allergy Clin Immunol. 2003 Sep;23(3):483-93.

26. Calderon MA, Cox LS. Monoallergen sublingual immunotherapy versus multiallergen subcutaneous immunotherapy for allergic respiratory diseases: a debate during the AAAAI 2013 Annual Meeting in San Antonio, Texas. J Allergy Clin Immunol Pract. 2014 MarApr;2(2):136-43.

27. Amar SM, Harbeck RJ, Sills M, Silveira LJ, O’Brien H, Nelson HS. Response to sublingual immunotherapy with grass pollen extract: monotherapy versus combination in a multiallergen extract. J Allergy Clin Immunol. 2009 Jul;124(1):150-6. e1-5.

28. Nelson HS. Multiallergen immunotherapy for allergic rhinitis and asthma. J Allergy Clin Immunol. 2009 Apr;123(4):763-9. 


\section{Clinical and Experimental Otorhinolaryngology}

Supplementary Table 1. Questionnaire regarding the prescription patterns for allergic rhinitis

Demographics

1. What is your specialty?

(1) Internal medicine (2) Pediatrics (3) Otorhinolaryngology-head and neck surgery (4) Others

2. How long have you been carry on your specialty?

(1) less than 5 years (2) 5 to 10 years (3) 10 to 15 years (4) 15 to 20 years (5) more than 20 years

3. Where is your practice located?
(1) Seoul/Gyeonggi/lncheon
(2) Daejeon/Chungcheong
(3) Daegu/Busan/Ulsan/Gyeongsang
(4) Gwangju/Jeolla
(5) Kangwon
(6) Jeju

4. Which is your practice type?

(1) University hospital (2) General hospital (3) Local hospital (4) Private clinic (5) Others

\section{Diagnosis}

5. Which do you think is the most important thing to diagnosis allergic rhinitis?
(1) Clinical symptoms
(2) Skin prick test (SPT)
(3) Serum specific IgE test
(4) Nasal endoscopy
(5) Nasal provocation test

6. Which do you use to definitely diagnose allergic rhinitis?
(1) SPT
(2) MAST or RAST
(3) ImmunoCAP
(4) SPT+MAST/RAST
(5) SPT+ImmunoCAP
(6) Nothing

7. How much proportion of allergic rhinitis patients in your clinic?
(1) $\leq 10 \%$
(2) $11-20 \%$
(3) $21-30 \%$
(4) $31-40 \% \quad$ (5) $>40 \%$

8. Which is the most common season in allergic rhinitis?
(1) Spring
(2) Summer
(3) Autumn
(4) Winter
(5) Not predominant

9. Which is your classification about allergic rhinitis? (select all that apply)

(1) Intermittent and persistent (2) Seasonal and perennial (3) Mild, moderate, severe

(4) Mild intermittent, moderate to severe intermittent, mild persistent, and moderate to severe persistent

10. Which guideline do you use for diagnosis of allergic rhinitis?
(1) ARIA guideline
(2) AAO-HNSF guideline
(3) KAAACI guideline
(4) The KRS guideline
(5) Others
(6) Nothing

11. How commonly allergic rhinitis accompanied with asthma?
(1) $\leq 5 \%$
(2) $6-10 \%$
(3) $11-15 \%$
(4) $16-20 \%$
(5) $>20 \%$

\section{Treatment}

12. Which is the initial medication for treatment of AR?

(1) Antihistamine, oral (2) Antihistamine, nasal spray (3) Leukotriene receptor antagonist (LTA) (4) Intranasal steroid spray (INS)

(5) Decongestant (6) Others

13. Which is your mostly used combination for treatment of AR?

$\begin{array}{lllllll}\text { (1) INS+oral antihistamine (2) INS+nasal antihistamine } & \text { (3) INS+LTA } & \text { (4) Oral antihistamine+LTA } & \text { (5) Oral antihistamine+decongestant }\end{array}$

(6) INS+oral antihistamine+LTA (7) INS+oral antihistamine+decongestant (8) Others

14. How long do you prescribe medication?

(1) Less than 2 weeks (2) 2 weeks to 4 weeks (3) 4 weeks to 8 weeks (4) More than 8 weeks

15. How about patients' compliance to medication?
(1) $\leq 50 \%$
(2) $51-80 \%$
(3) $81-99 \%$
(4) $100 \%$ 
Supplementary Table 1. Continued from the previous page

16. Do you explain about allergen avoidance and environmental control?

(1) All allergen (2) House dust mite (HDM) (3) Pollen (4) Animal dander (5) None

17. Do you recommend surgery to your patient?

(1) No $\begin{array}{lllll}\text { (2) } \leq 10 \% & \text { (3) } 11-20 \% & \text { (4) } 21-30 \% & \text { (5) } 31-40 \% & \text { (6) }>40 \%\end{array}$

\section{Immunotherapy}

18. Do you prescribe immunotherapy in your practice?
(1) No
(2) $\leq 10 \%$
(3) $11-20 \%$
(4) $21-30 \%$
(5) $31-40 \%$
(6) $>40 \%$

If you answered (1) to number 19 and quit survey, If you answered others to number 20

19. What is the reason not to prescribe immunotherapy in your practice?

(1) Distrust of its therapeutic effect (2) Require long term treatment duration (3) Lack of facilities or trained health professionals

(4) Lack of practice (5) Others

20. Which is your preferred method of immunotherapy?

(1) SCIT (2) SLIT (3) Both (4) Others

21. Which do you use to detect allergen for immunotherapy? (select all that apply)
(1) SPT (2) MAST/RAST
(3) ImmunoCAP
(4) Nasal provocation test
(5) None

22. For which type of allergens are you using immunotherapy (select all that apply)

(1) HDM (2) Mold (3) Pollens (4) Cockroach (5) Animal dander (6) Others

23. How many allergen extracts do you mix in immunotherapy?

(1) One (2) Two (3) More than three

24. How about the proportion of allergen extracts in immunotherapy?

(

25. How long do you recommend duration of immunotherapy?

$\begin{array}{llllll}\text { (1) } 1 \text { year (2) } 2 \text { years (3) } 3 \text { years } & \text { (4) } 4 \text { years } & \text { (5) } 5 \text { years (6) More than } 6 \text { years }\end{array}$

26. How about completion rate of whole schedule of immunotherapy

26-1 SCIT

$\begin{array}{lllll}\text { (1) } \leq 20 \% & \text { (2) } 21-40 \% & \text { (3) } 41-60 \% & \text { (4) } 61-80 \% & \text { (5) } 81-100 \%\end{array}$

$\begin{array}{lllll}\text { (1) } \leq 20 \% & \text { (2) } 21-40 \% & \text { (3) } 41-60 \% & \text { (4) } 61-80 \% & \text { (5) } 81-100 \%\end{array}$

27. Have you ever observed adverse reactions in immunotherapy?

(1) SCIT (detail:__ ) (2) SLIT (detail:__ ) (3) None

28. Have you ever discontinued immunotherapy due to adverse reactions?

(1) SCIT (detail:__ ) (2) SLIT (detail:__ ) (3) None

MAST, multiple allergen simultaneous test; RAST, radio allergy sorbent test; ARIA, Allergic Rhinitis and its Impact on Asthma; AAO-HNSF, American Academy of Otolaryngology-Head and Neck Surgery Foundation; KAAACI, Korean Academy of Asthma, Allergy and Clinical Immunology; KRS, Korean Rhinologic Society; AR, allergic rhinitis; SCIT, subcutaneous immunotherapy; SLIT, sublingual immunotherapy. 